\title{
Peritonitis Rate in Children on Chronic Peritoneal Dialysis Impact on Survival
}

\author{
Reyner Loza ${ }^{1,2 *}$, Vanessa K Ramírez ${ }^{3}$, María Sarmiento ${ }^{3}$, and Edwin J Yong ${ }^{3}$ \\ ${ }^{1}$ Nephrology Paediatric Unit, Department of Pediatrícs, Cayetano Heredia National Hospital, Peru \\ ${ }^{2}$ Professor Associate, Department of Medical Clinic, Pediatrics Section, Alberto Hurtado School of Medicine, Cayetano Heredia peruvian \\ University, Lima, Peru \\ ${ }^{3}$ Department of Medical Clinic, Alberto Hurtado School of Medicine, Cayetano Heredia Peruvian University, Lima, Peru
}

*Corresponding author: Reyner Loza, Pediatric Nephrologist, Medico Assistant Unidad de Nephrology Paediatric, Department of Pediatrícs, Cayetano Heredia National Hospital, Lima, Peru; E-mail: reyner.loza@upch.pe

Received: 25 May, 2020 | Accepted: 09 Jun, 2020 | Published: 20 Jun, 2020

Citation: Loza R, Ramírez VK, Sarmiento M, Yong EJ (2020) Peritonitis Rate in Children on Chronic Peritoneal Dialysis Impact on Survival. Int J Nephrol Kidney Fail 6(2): dx.doi.org/10.16966/2380-5498.196

Copyright: (C) 2020 Loza R, et al. This is an open-access article distributed under the terms of the Creative Commons Attribution License, which permits unrestricted use, distribution, and reproduction in any medium, provided the original author and source are credited.

\section{Abstract}

Objective: Determination of the rate of peritonitis in children with Chronic Kidney Disease (CKD) on peritoneal dialysis therapy, factors associated and the impact on survival.

Materials and Methods: Descriptive, retrospective, analytical study of children under 18 years of age with CKD on peritoneal dialysis (PD) from 2001 to 2015 at the Cayetano Heredia National Hospital (HNCH) in Lima, Perú.

Results: 196 children treated by PD at the PD unit over a 15 -year period were included in the study. Age: $10.73 \pm 4.55$ years, 102 males ( $52.04 \%)$, and 94 females (47.96\%). Main etiology of CKD was glomerular nephropathy, 81 (41.33\%). Three hundred ninety-two cases of peritonitis were recorded, representing 0.75 cases of peritonitis per at-risk patient-year, with a probability of one case every 16 months. The variables independently associated with peritonitis comprised orifice infection ( $\mathrm{OR}: 2.23 ; 95 \% \mathrm{Cl}$ 1.06-4.70; $\mathrm{p}=0.04)$, being male (OR: $2.08 ; 95 \% \mathrm{Cl} 1.08-4.02 ; \mathrm{p}=0.03$ ), catheter extension change (OR: 2.58; $95 \% \mathrm{Cl} 1.32-5.05 ; \mathrm{p}=0.01$ ), and being from province other than the Capital (OR: $0.45 ; 95 \% \mathrm{Cl} 0.24-0.90 ; \mathrm{p}=0.02$ ). Peritonitis had no influence on patient survival ( $\mathrm{HR}: 0.24 ; 95 \% \mathrm{Cl} 0.09-0.68 ; \mathrm{p}=0.07$ ). Overall survival was $93.9 \%$ at one year and $74 \%$ at five years.

Conclusions: The rate of peritonitis in children is similar to what has been reported in other studies. Factors associated with peritonitis are being male, orifice infection, and catheter extension change, while residing in provinces was a protective factor. And peritonitis had no influence on survival.

Keywords: Peritoneal Dialysis; Chronic Kidney Disease; Peritonitis; Children

\section{Introduction}

CKD is defined as an irreversible state of renal damage and/or a progressive decline in renal function. The 2012 Kidney Disease guide, Improving Global Outcomes (KDIGO) for evaluating and managing Chronic Kidney Disease (CKD), reviewed the classification of the clinical practice guide for the Kidney Disease Outcomes Initiative (KDOQUI) in 2002 and a unanimous definition of this concept was established. Five stages of chronic kidney disease have been defined in children, especially for those older than 2 years of age, with the last two being indicators of renal replacement therapy (RRT) [1,2]. In Chile, the incidence of CKD with a glomerular filtration rate (GFR) of less than $30 \mathrm{ml} / \mathrm{min} 1.73 \mathrm{~m}^{2}$ in children under 18 years of age was estimated to be approximately 5.7 per million inhabitants, equating to a prevalence of 42.5 [3-5].

Between 2014 to 2015 in Lima and Callao, Peru, the number of children under 18 years of age receiving RRT was 14 children/million population, and the number of children receiving RRT was 5 children/ million population [6]. RRT needs to be started in children when the GFR drops below $30 \mathrm{ml} / \mathrm{min} / 1.73 \mathrm{~m}^{2}$, i.e., at stage 4 or 5 [7].

RRT includes renal transplantation, hemodialysis (HD), and PD. Although renal transplantation is the most commonly used modality, peritoneal dialysis is effective and it is a suitablwe option for achieving proper metabolic and nutritional control [8-10]. In recent years, 70\% of the pediatric patients in the United States has been treated with PD, and approximately 60\% in Europe and 93\% in Japan [11].

There are two types of chronic PD modalities: Continuous Ambulatory Peritoneal Dialysis (CAPD) and Automated Peritoneal Dialysis (APD) [12,13].

Peritoneal dialysis in pediatric patients can lead to infectious complications, such as peritonitis. This type of infection can have a pronounced impact on the long-term prognosis as a result of a reduction in the lifetime of the peritoneal membrane [14,15]. 
At the international level, peritonitis rates are based on foreign populations. This is why this study sought to determine the rate of peritonitis in children with chronic renal failure on chronic PD therapy in Peru, and to evaluate factors associated with the presence of peritonitis and its impact on survival.

\section{Materials and Methods}

A descriptive, retrospective, and analytical study was carried out involving patients under 18 years of age with CKD who were undergoing PD. This study was undertaken in the chronic PD unit of the Cayetano Heredia University service and the pediatric nephrology unit of the HNCH in Lima, Peru from January 2001 to June 2015. The study was approved by a hospital ethics committee. No sample size was calculated for the entire population of children enrolled in the PD program during that time period. The inclusion criteria comprised CKD patients who were under 18 years of age, undergoing PD, and participated in the PD program for at least three months, for whom the medical data was complete. Six patients were excluded as they participated in the program for less than 3 months, while 5 patients whose catheter was placed in another center and 1 patient with incomplete data were also excluded. The study variables were selected (Appendix 1) to collect data by reviewing medical records and PD follow-up sheets, as well as to create a database using Microsoft Excel 2010. The rate of peritonitis was then determined, defined as a cloudy peritoneal fluid with more than 100 leukocytes $/ \mathrm{mm}^{3}$, or in the case of a positive culture, the time of the appearance of the first episode of peritonitis, the percentage of peritonitis-causing microorganisms, and the causes of hospitalization were described.

Stata software version 14 was used for the statistical analysis.

A description of the general population was made. In the bivariate analysis, the exposure variables were: age, gender, place of origin, region, the parents' level of education, nutritional status, the etiology, the dialysis modality, the catheter type, the initial membrane type, catheter extension change, orifice infection, dialysis, and dialysis operator adequacy. Having peritonitis or not was the outcome variable. A multiple multivariate logistic regression analysis was then performed to evaluate the factors related to the probability of having peritonitis. Two models were devised for this purpose. The first model adjusted the demographic variables: age, gender, place of origin, region, and the parents' level of education, nutritional status, and etiology, with initial membrane type and orifice infection. The second model adjusted the above-mentioned demographic variables with the dialysis modality, catheter type, dialysis operator, catheter extension change, and orifice infection.

Finally, a survival analysis was performed to generate the KaplanMeier survival curve and the overall survival table for the study period, with the outcome variable being mortality (living or dying). A Cox regression multivariate analysis was performed to evaluate the factors related to the probability of living or dying during the period. For this, two models were devised. The first model adjusted the demographic variables (as described for the peritonitis models) with peritonitis, the initial and the final membrane type, the average $\mathrm{Kt} / \mathrm{V}$, and orifice infection. The second model adjusted the demographic variables described above with the dialysis modality, the catheter type, the dialysis operator, catheter extension change, and peritonitis.

The categorical variables were compared with chi-squared and Fisher's test, the continuous variables with a test (Student's $t$ ) for independent data when the variable had a normal distribution, and the Wilcoxon test to compare averages without a normal distribution. For the analysis, a $\mathrm{p} \leq 0.05$ was considered as statistically significant.

\section{Results}

Two hundred and eight patients with CKD who underwent PD at the Hospital Nacional Cayetano Heredia $(\mathrm{HNCH})$ were registered between January 2001 and June 2015. One hundred ninety-six of these patients met the inclusion criteria. The population ranged from 0 to 17 years of age, with a mean of $10.73 \pm 4.55 \mathrm{DE}, 102(52.04 \%)$ were male and $94(47.96 \%)$ were female. For $128(65.31 \%)$ the capital was their place of residence, 137 (69.9\%) lived in coastal areas, 45 (22.96\%) lived in the highlands, and $14(7.14 \%)$ lived in the Jungle. One hundred and nine (57.67\%) had an age-appropriate body mass index (BMI), 54 (28.57\%) were below this BMI and 26 (13.77\%) were above this BMI. The etiologies of the kidney disease were: glomerular nephropathy in 81 patients $(41.33 \%)$, hypoplasia/dysplasia in 52 patients $(26.53 \%)$, and urinary tract malformations in 31 patients $(15.82 \%)$. Spiral catheters with a double cuff, which were used by 132 patients (67.35\%), and was the most commonly used type of catheter. The peritoneal membrane type was high-average for 67 patients $(34.18 \%)$ at the beginning and the mixed form for 76 patients $(38.78 \%)$ at the end. Ninety-eight patients $(50.00 \%)$ did not undergo catheter extension change. Orifice infection was detected in 65 patients $(33.16 \%)$, and the crude death rate was $30(15 \%)$ with the main cause of death being sudden and cardiovascular death 14 (46.66\%) and none associated with peritonitis. Manual PD, which was used by 176 patients $(89.8 \%)$ was the most commonly used modality. For 130 patients $(66.33 \%)$, it was performed by their mother, while 37 patients $(18.88 \%)$ did it themselves (Table 1). There were 392 episodes of peritonitis in 139 patients on PD; 98 patients (50\%) with one to three episodes and 41 patients $(20.92 \%)$ with four or more episodes. Fifty-seven patients (29.08\%) did not experience an episode of peritonitis. Eighty-five (21.68\%) episodes were diagnosed by a culture, $233(59.44 \%)$ by increased cellularity in the peritoneal fluid, and $74(18.88 \%)$ by both of these criteria. The peritonitis rate amounted to 0.75 episodes of peritonitis/patient-year risk and a probability of one episode every 16 months. The causal germ of these events was isolated in 159 cases (40.56\%): in most of the cases, it was Gram-positive 100 (25.5\%), Candida spp.13 (3.3\%) and Gramnegative 39 (8.68\%) (Table 2). Infectious diseases were the main cause of 251 of the recorded hospital admissions, with peritonitis being the most prevalent in 90 cases (35.86\%) (Table 3). The bivariate analysis of having/not having peritonitis showed that being young (OR: 0.89; 95\% CI 0.82-0.96) and from a province other than the capital (OR: 0.46; $95 \%$ CI $0,24-0.87$ ) were protective against peritonitis. On the other hand, cycler mode (OR: 8.86; 95\% CI 1.15-67.90), catheter extension changes (OR: 2.36; 95\% CI 1.24-4.48), orifice infection (OR: 2.24; 95\% CI 1.08-4.63), and dialysis performed by third parties (OR: 0.39 ; $95 \%$ CI 0.19-0.83) were significant statistical indexes of a higher probability of infection. The remaining items were not statistically significant (Table 4). In the multivariate analysis, the variables independently associated with peritonitis as a risk factor were: being male (OR: 2.08; 95\% CI 1.08-4.02; $\mathrm{p}=0.03$ ), orifice infection (OR: 2.23 ; 95\% CI 1.06$4.70 ; \mathrm{p}=0.04$ ), and catheter extension change (OR: 2.58 ; $95 \%$ CI $1.32-$ $5.05 ; \mathrm{p}=0.01$ ). From a province other than the capital (OR: $0.45 ; 95 \%$ CI 0.24-0.90; $\mathrm{p}=0.02$ ) was a protective factor (Table 5). Likewise, the probability of peritonitis in the pediatric patients on $\mathrm{PD}$ was evaluated (Figure1). In the first year, $88.2 \%$ (95\% CI 0.83-0.92) did not have peritonitis, and in the fifth year this figure was $23 \%$ (95\% CI 0.17 0.31 . The impact of peritonitis on the patient survival curve was also evaluated. This was statistically significant with a $p=0.017$ (Figure 2). The general survival analysis is described with the Kaplan-Meier curve (Figure 3). In the first year, the survival rate was 93.9\% (95\% CI: 0.890.96 ) and in the fifth year it was $74 \%$ (95\% CI: 0.62-0.83). Bivariate analysis of the mortality outcome showed that the level of education 
Table 1: Population characteristics.

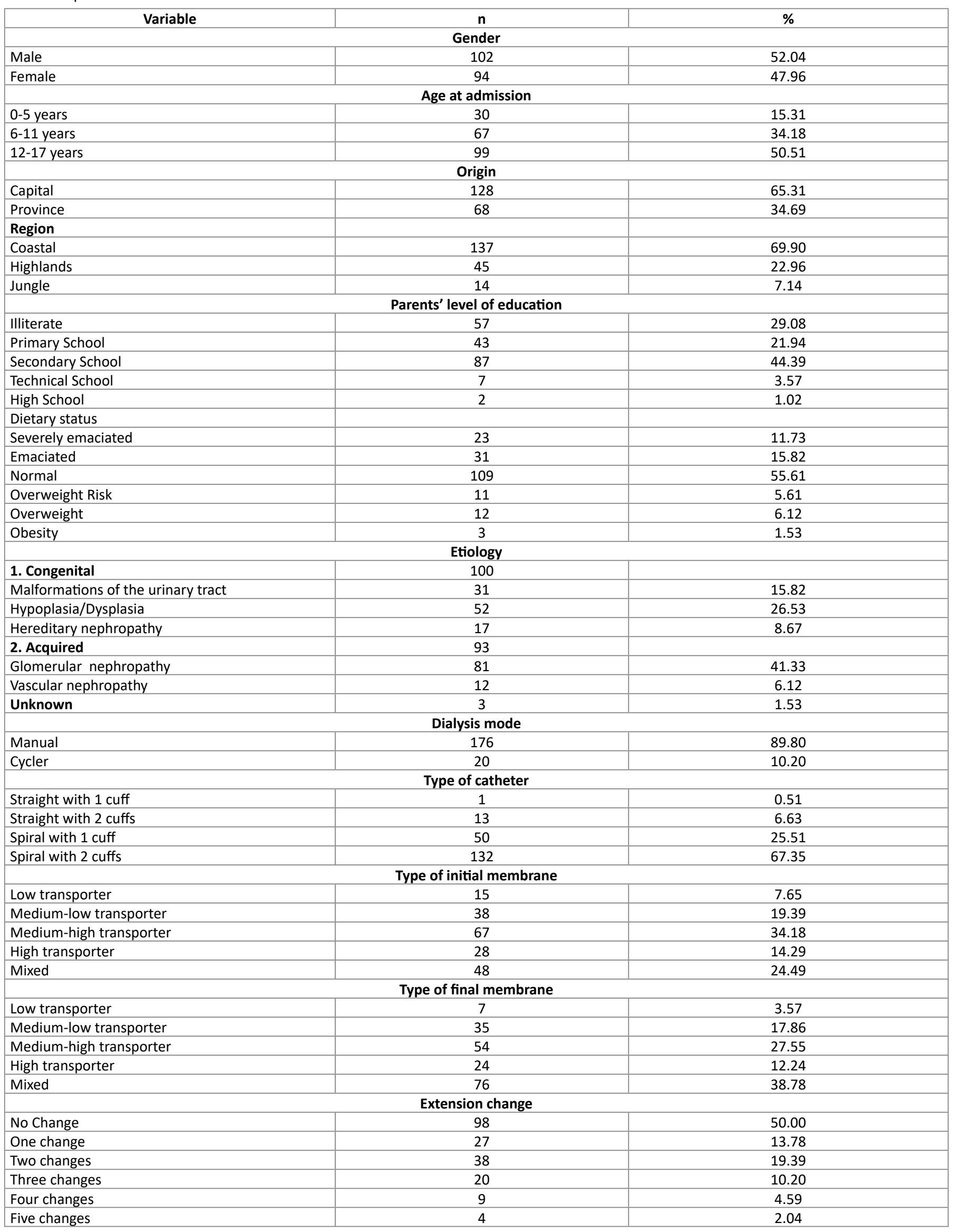




\begin{tabular}{|c|c|c|}
\hline \multicolumn{3}{|c|}{ Orifice infection } \\
\hline Yes & 65 & 33.16 \\
\hline None & 131 & 66.84 \\
\hline \multicolumn{3}{|c|}{ Adequacy of the dialysis } \\
\hline Normal & 114 & 58.16 \\
\hline Below normal range & 82 & 41.84 \\
\hline \multicolumn{3}{|c|}{ Peritonitis } \\
\hline Yes & 139 & 70.92 \\
\hline No & 57 & 29.08 \\
\hline \multicolumn{3}{|c|}{ Current situation } \\
\hline Hemodialysis & 47 & 23.98 \\
\hline Transplanted & 42 & 21.43 \\
\hline Switched to EsSalud & 37 & 18.88 \\
\hline Continued on peritoneal dialysis & 35 & 17.86 \\
\hline Deceased & 30 & 15.31 \\
\hline Ceased treatment & 5 & 2.55 \\
\hline \multicolumn{3}{|c|}{ Final condition } \\
\hline Alive & 166 & 84.69 \\
\hline Deceased & 30 & 15.31 \\
\hline \multicolumn{3}{|c|}{ Operator } \\
\hline Patient & 37 & 18.88 \\
\hline Mother & 130 & 66.33 \\
\hline Father & 15 & 7.65 \\
\hline Brother & 6 & 3.06 \\
\hline Father and Mother & 3 & 1.53 \\
\hline Other & 5 & 2.55 \\
\hline
\end{tabular}

Table 2: The microbial entities identified in peritonitis events.

\begin{tabular}{|l|c|c|}
\hline \multicolumn{1}{|c|}{ Microorganism } & Frequency (n = 392) & Percentage (\%) \\
\hline Staphylococcus aureus & 48 & 12.24 \\
\hline Albococcus epidermidis & 46 & 11.73 \\
\hline Candida spp. & 13 & 3.32 \\
\hline Acinetobacter spp. & 9 & 2.30 \\
\hline Pseudomonas spp. & 7 & 1.79 \\
\hline Klebsiella spp. & 6 & 1.53 \\
\hline Escherichia coli & 6 & 1.53 \\
\hline Enterobacter spp. & 4 & 1.53 \\
\hline Staphylococcus saprophyticus & 2 & 1.02 \\
\hline Polymicrobial: & 12 & 0.51 \\
\hline Other** & 233 & 3.06 \\
\hline Negative culture & 392 & 100 \\
\hline Total & \multicolumn{2}{|c|}{64} \\
\hline * Staph. epidermidis + Trichosporon, Staph. Epidermidis + Staph. \\
$\begin{array}{l}\text { Saprophyticus } \\
\text { **Bacillus spp., Flavobacterium spp., Serratia } \\
\text { viridians, Citrobacter spp., Hemophilus. }\end{array}$ & Streptococcus \\
\hline
\end{tabular}

(HR: 0.45; 95\% CI 0.22-0.93; $\mathrm{p}<0.05$ ), orifice infection (HR: 0.33; 95\% CI $0.14-0.84 ; \mathrm{p}<0.05$ ), and dealing with peritonitis (HR: $0.32 ; 95 \% \mathrm{CI}$ $0.15-0.67 ; \mathrm{p}<0.05)$ were associated with a lower probability of death. The remaining items were not statistically significant (Table 6). In the multivariate analysis, the peritonitis variable proved to be a protective factor in terms of mortality (HR: 0.24; 95\% CI 0.09-0.68; $\mathrm{P}=0.007$ ).

\section{Discussion}

Our study analyzed a total of 196 patients over a period of 15 years. The average age at the time of admission to the PD service was 10.73 years, similar to what has been found in Mexico, where the average age was 11.4 years. There were a higher proportion of males (52.04\%),
Table 3: Reason for the hospitalization.

\begin{tabular}{|l|c|c|}
\hline Reason for the hospitalization & $\mathbf{n}$ & $\mathbf{\%}$ \\
\hline Infectious & 116 & 46.22 \\
\hline Cardiovascular & 55 & 21.91 \\
\hline Surgical & 21 & 8.37 \\
\hline Catheter related & 12 & 4.78 \\
\hline Neuro-Psychological & 10 & 3.98 \\
\hline Respiratory & 6 & 2.39 \\
\hline Gastrointestinal & 7 & 2.79 \\
\hline Hydroelectrolytic disorders & 4 & 1.59 \\
\hline Other* & 20 & 7.97 \\
\hline Total & 251 & 100.00 \\
\hline
\end{tabular}

*Cessation of treatment (4), anasarca (1), digoxin toxicity (1), and unknown (14).

which matches the general trend in Latin America. [16,17]. In terms of their place of origin, we found that 128 patients (65.31\%) came from the capital, while $68(34.69 \%)$ came from areas other than the capital, given that the PD center of the Cayetano Heredia Hospital was the only national reference center.

The main etiology of the CKD in our population was glomerular nephropathy, which affected 81 patients (41.33\%). This is in keeping with what has been found in North America, unlike the Spanish Pediatric Registry, where structural abnormalities were the most common etiology [16]. The most commonly used dialysis modality in our population was CAPD, which was used in 176 patients $(89.9 \%)$, like what has been found in Chile, where $91.17 \%$ of the patients used this modality [17]. Peritonitis is the most frequent complication of PD, with 392 cases in our study. Analysis of the causative agent showed that 104 episodes (26.53\%) were due to Gram-positive entities, with Staphylococcus aureus being the most prevalent. These findings are compatible with a multicenter study in Chile, where $50 \%$ of the 
Table 4: Bivariate analysis between the proposed variables and peritonitis.

\begin{tabular}{|c|c|c|c|c|c|c|c|c|}
\hline & & \multicolumn{2}{|c|}{ Non peritonitis } & \multicolumn{2}{|c|}{ Peritonitis } & \multirow[t]{2}{*}{$\mathbf{p}$} & \multirow[t]{2}{*}{ OR } & \multirow[t]{2}{*}{$\mathrm{Cl}$} \\
\hline & & $\mathbf{n}$ & $\%$ & $\mathbf{n}$ & $\%$ & & & \\
\hline \multirow{2}{*}{ Gender } & Female & 33 & 35.11 & 61 & 64.89 & \multirow{2}{*}{0.08} & \multirow{2}{*}{1.76} & \multirow{2}{*}{$0.94-3.27$} \\
\hline & Male & 24 & 23.53 & 78 & 76.47 & & & \\
\hline \multirow{2}{*}{ Origin } & Capital & 30 & 23.44 & 98 & 76.56 & \multirow{2}{*}{0.02} & \multirow{2}{*}{0.46} & \multirow{2}{*}{$0.24-0.87$} \\
\hline & Province & 27 & 39.71 & 41 & 60.29 & & & \\
\hline \multirow{3}{*}{ Region } & Coastal & 35 & 25.55 & 102 & 74.45 & \multirow{3}{*}{0.48} & \multirow{3}{*}{0.83} & \multirow{3}{*}{$0.51-1.36$} \\
\hline & Highlands & 20 & 44.44 & 25 & 55.56 & & & \\
\hline & Jungle & 2 & 14.29 & 12 & 85.71 & & & \\
\hline \multirow{2}{*}{ Level of education } & Illiterate & 18 & 31.58 & 39 & 68.42 & \multirow{2}{*}{0.62} & \multirow{2}{*}{1.18} & \multirow{2}{*}{$0.60-2.31$} \\
\hline & Studies & 39 & 28.06 & 100 & 71.94 & & & \\
\hline \multirow{3}{*}{ Nutritional condition } & Normal & 35 & 29.17 & 85 & 70.83 & \multirow{3}{*}{0.56} & \multirow{3}{*}{1.11} & \multirow{3}{*}{$0.77-1.60$} \\
\hline & Above normal BMI & 2 & 13.33 & 13 & 86.76 & & & \\
\hline & Below normal BMI & 14 & 25.93 & 40 & 74.07 & & & \\
\hline \multirow{2}{*}{ Etiology } & Congenital & 24 & 24.00 & 76 & 76.00 & \multirow{2}{*}{0.08} & \multirow{2}{*}{0.57} & ב 100 \\
\hline & Acquired & 33 & 35.48 & 60 & 64.52 & & & $0.30-1.07$ \\
\hline & Manual & 56 & 31.82 & 120 & 68.18 & & & \\
\hline Dlailysis mode & Cycler & 1 & 5.00 & 19 & 95.00 & 0.04 & 8.86 & $1.15-6 \% .90$ \\
\hline T. & Rectum & 2 & 14.29 & 12 & 85.71 & 020 & 020 & בר 1902 \\
\hline Type or catreter & Spiral & 55 & 30.22 & 127 & 69.78 & 0.22 & 0.50 & $0.05-1.1 /$ \\
\hline & Low & 5 & 33.33 & 10 & 66.67 & & & \\
\hline & Medium-low & 16 & 42.11 & 22 & 57.89 & & & \\
\hline Iype of Initial & Medium-high & 19 & 28.36 & 48 & 71.64 & 0.07 & 1.26 & $0.98-1.62$ \\
\hline & High & 6 & 21.43 & 22 & 78.57 & & & \\
\hline & Mixed & 11 & 22.92 & 37 & 77.08 & & & \\
\hline Cutoncian shana & No changes & 37 & 37.76 & 61 & 62.24 & 001 & 20 & 10 \\
\hline Excension change & With changes & 20 & 20.41 & 78 & 79.59 & 0.01 & 2.30 & $1.24-4.40$ \\
\hline Orifico infoction & Did not occur & 44 & 34.11 & 85 & 65.89 & בחת & $2 ? 1$ & 602 \\
\hline Urince Inrection & Occurred & 12 & 18.75 & 52 & 81.25 & 0.03 & $2 . \angle 4$ & $1.08-4.03$ \\
\hline Aderuacu of dialucic & Normal & 34 & 29.82 & 80 & 70.18 & 070 & 109 & 050201 \\
\hline Aaequacy or alalysis & Below normal range & 23 & 28.05 & 59 & 71.95 & 0.19 & 1.09 & $0.38-2.04$ \\
\hline Dialvcis onerator & Third parties & 40 & 25.16 & 119 & 74.84 & 001 & 039 & $019-03$ \\
\hline Dialysis operator & Patient & 17 & 45.95 & 20 & 54.05 & 0.01 & 0.39 & $0.19-0.83$ \\
\hline Age at admission & & $12.25 \pm 3.9$ & 29.08 & $10.14 \pm 4.71$ & 70.92 & 0.04 & 0.89 & $0.82-0.96$ \\
\hline
\end{tabular}

Table 5: Multivariate analysis between the proposed variables and peritonitis.

\begin{tabular}{|l|c|c|c|}
\hline \multicolumn{1}{|c|}{ Variable } & P & OR & Cl \\
\hline Male & 0.03 & 2.08 & $1.08-4.02$ \\
\hline Orifice Infection & 0.04 & 2.23 & $1.06-4.70$ \\
\hline Catheter Extension Change & 0.01 & 2.58 & $1.32-5.05$ \\
\hline Province & 0.02 & 0.45 & $0.24-0.90$ \\
\hline
\end{tabular}

isolated microorganisms were Gram-positive [18]. There were 13 cases (3.32\%) of fungal peritonitis, in our population, which is less frequent than what has been reported in studies from Africa (7\%) and Central America (10\%), and the SCOPE study (8\%) [19-21]. Unlike the 20\% reported in the literature, [22], 59.44\% of the cultures were negative in our study. This finding is probably related to the early onset of antibiotic therapy without a previous culture. The multivariate analysis of having/not having peritonitis did not show significant differences in terms of age, region, level of education, nutritional status, etiology, dialysis modality, catheter type, initial membrane type, or dialysis and dialysis operator adequacy, as corroborated by a number of variables studied in the literature $[23,24]$. However, our series found that the variables independently associated with peritonitis risk factors were orifice infection, being male, and catheter extension changes not described until today. Coming from a province other than the Capital, on the other hand, was a protective factor; this factor could be related that peritonitis would induce greater care in child. Despite some studies showing that gender is not a statistically significant factor [25], it turned out to be relevant in our population, possibly because male children have a lower level of self-care regarding personal hygiene when performing the dialysis procedure. In regard to orifice infection, this association has been seen in bivariate but not multivariate analyses [26]. The literature does not indicate that there is a correlation with catheter extension change. In our population, this could be due to more handling of the catheter or a lack of preventive use.

On the other hand, most likely, the patients coming from a province other than the capital, i.e., a rural area, have less risk of peritonitis. This has not been reported in the literature. Our hypothesis is based on consideration of the climate and increased awareness of the disease. 
Table 6: Bivariate analysis between the proposed variables and mortality.

\begin{tabular}{|c|c|c|c|c|c|c|c|c|}
\hline & & \multicolumn{2}{|c|}{ Alive } & \multicolumn{2}{|c|}{ Deceased } & \multirow[t]{2}{*}{$\mathbf{p}$} & \multirow[t]{2}{*}{ HR } & \multirow[t]{2}{*}{$\mathrm{Cl}$} \\
\hline & & $\mathbf{n}$ & $\%$ & $\mathbf{n}$ & $\%$ & & & \\
\hline \multirow{2}{*}{ Gender } & Female & 80 & 85.11 & 14 & 14.89 & \multirow{2}{*}{0.92} & \multirow{2}{*}{0.96} & \multirow{2}{*}{$0.46-2.01$} \\
\hline & Male & 86 & 84.31 & 16 & 15.69 & & & \\
\hline \multirow{2}{*}{ Origin } & Capital & 108 & 84.38 & 20 & 15.63 & \multirow{2}{*}{0.66} & \multirow{2}{*}{1.19} & \multirow{2}{*}{$0.55-2.57$} \\
\hline & Province & 58 & 85.29 & 10 & 14.71 & & & \\
\hline \multirow{3}{*}{ Region } & Coastal & 117 & 85.40 & 20 & 14.60 & \multirow{2}{*}{0.43} & \multirow{3}{*}{1.24} & \multirow{3}{*}{$0.72-2.16$} \\
\hline & Highlands & 37 & 82.22 & 8 & 17.78 & & & \\
\hline & Jungle & 12 & 85.71 & 2 & 14.29 & & & \\
\hline \multirow{2}{*}{ Level of education } & Illiterate & 42 & 73.68 & 15 & 26.32 & \multirow{2}{*}{0.03} & \multirow{2}{*}{0.45} & \multirow{2}{*}{$0.22-0.93$} \\
\hline & Formal education & 124 & 89.21 & 15 & 10.79 & & & \\
\hline \multirow{3}{*}{ Nutrition status } & Normal BMI & 105 & 87.50 & 15 & 12.50 & \multirow{3}{*}{0.73} & \multirow{3}{*}{1.08} & \\
\hline & Above normal BMI & 13 & 86.67 & 2 & 13.33 & & & $0.67-1.67$ \\
\hline & Below normal BMI & 46 & 85.19 & 8 & 14.81 & & & \\
\hline & Congenital & 83 & 83.00 & 17 & 17.00 & & & \\
\hline Etiology & Acquired & 80 & 86.02 & 13 & 13.98 & 0.83 & 0.92 & $0.44-1.90$ \\
\hline & Manual & 150 & 85.23 & 26 & 14.77 & & & \\
\hline Dialysıs mode & Cycler & 16 & 80.00 & 4 & 20.00 & 0.91 & 0.94 & $0.32-2.15$ \\
\hline & Rectum & 12 & 85.71 & 2 & 14.29 & & & \\
\hline Type of catheter & Spiral & 154 & 84.62 & 28 & 15.38 & 0.58 & 1.50 & $0.36-6.35$ \\
\hline $\begin{array}{l}\text { Type of initial } \\
\text { membrane }\end{array}$ & Low & 15 & 100.00 & 0 & 0.00 & & & \\
\hline & Medium-low & 34 & 89.47 & 4 & 10.53 & & & \\
\hline & Medium-high & 59 & 88.06 & 8 & 11.94 & 0.12 & 1.22 & $0.90-1.65$ \\
\hline & High & 17 & 60.71 & 11 & 39.29 & & & \\
\hline & Mixed & 41 & 85.42 & 7 & 14.58 & & & \\
\hline & Low & 7 & 100.00 & 0 & 0.00 & & & \\
\hline & Medium-low & 32 & 91.43 & 3 & 8.57 & & & \\
\hline Type of final & Medium-high & 45 & 83.33 & 9 & 16.67 & 0.97 & 0.99 & $0.75-1.32$ \\
\hline & High & 15 & 62.5 & 9 & 37.50 & & & \\
\hline & Mixed & 67 & 88.16 & 9 & 11.84 & & & \\
\hline & Did not occur & 105 & 81.40 & 24 & 18.60 & & & \\
\hline Orifice infection & Occurred & 58 & 90.63 & 6 & 9.38 & 0.019 & 0.33 & $0.14-0.84$ \\
\hline & Normal & 95 & 83.33 & 19 & 16.67 & & & \\
\hline Dialysis adequacy & Below normal range & 71 & 86.59 & 11 & 13.41 & 0.65 & 0.85 & $0.40-1.78$ \\
\hline & Third parties & 134 & 84.28 & 25 & 15.72 & & & \\
\hline Dialysis operator & Patient & 32 & 86.49 & 5 & 13.51 & 0.66 & 0.80 & $0.31-2.10$ \\
\hline & Did not occur & 44 & 77.19 & 13 & 22.81 & & & \\
\hline Peritonitis & Occurred & 122 & 87.77 & 17 & 12.23 & 0.003 & 0.32 & $0.15-0.67$ \\
\hline & No changes & 81 & 82.65 & 17 & 17.35 & & & \\
\hline Extension change & With changes & 85 & 86.73 & 13 & 13.27 & 0.08 & 0.51 & $0.24-1.07$ \\
\hline Age at admission & & $10.95 \pm 4.48$ & 84.69 & $9.66 \pm 4.99$ & 15.31 & 0.27 & 0.95 & $0.88-1.04$ \\
\hline Average Ktv & & $2.52 \pm 1.16$ & 84.74 & $2.51 \pm 0.90$ & 15.26 & 0.94 & 0.98 & $0.68-1.42$ \\
\hline
\end{tabular}

Evaluation of the rate of peritonitis indicated a rate of 0.75 at-risk patients per year and a probability of an episode every 16 months, which is similar to a French study that reported an equal rate in children under 18 years [25]. Likewise, a similar description is provided in the North American Pediatric Renal Trials and Collaborative Studies annual report (NAPRTCS 2003), with a rate of 0.77 at-risk patients per year. Currently, a rate of 0.64 (NAPRTCS 2011) is described, and an episode every 18 months, as well as an inverse relationship between the patient's age and the rate of peritonitis in this age group [27,28]. It is important to take into account the economic, social, geographical, and cultural limitations of our country, for which this finding is relevant.

Likewise, the influence of peritonitis on patient survival was evaluated. Patients who addressed their peritonitis had a lower risk of death, and this relationship was significant. This differs from other series, where there was a direct relationship of peritonitis events with the risk of death [29,30]. Similarly, regarding general survival in pediatric patients on $\mathrm{PD}$, our study found that survival was $74 \%$ at 5 years, which differs with another study in which survival reached $89.5 \%[21,31]$. 


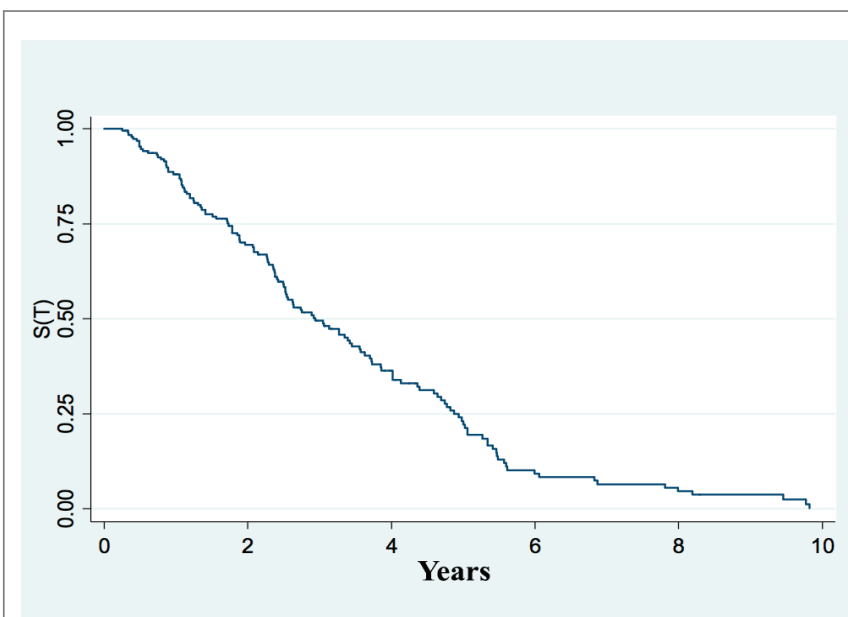

Figure 1: The probability of peritonitis in the pediatric patients.

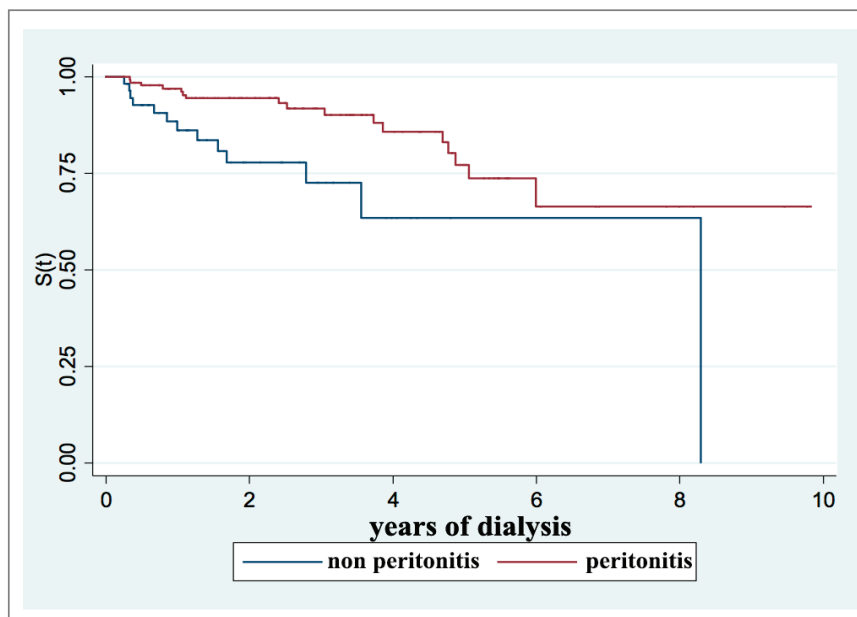

Figure 2: Survival of the pediatric patients with peritonitis vs. non peritonitis.

Log rank test $p=0.017$

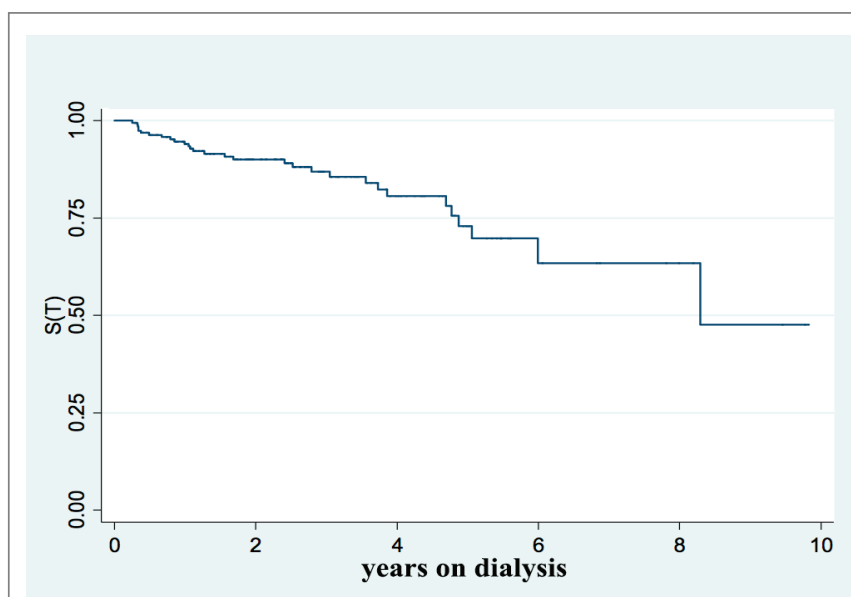

Figure 3: Overall survival of the pediatric patients on peritoneal dialysis.

\section{Appendix}

Appendix 1: Description of the study variables.

\begin{tabular}{|c|c|}
\hline Variable & Description \\
\hline Gender & Whether the patient was male or female \\
\hline Age & $\begin{array}{l}\text { The number of years from the date of birth } \\
\text { until the time renal replacement therapy with } \\
\text { peritoneal dialysis was started }\end{array}$ \\
\hline Place of origin & $\begin{array}{l}\text { Whether the patient lived in the capital or in } \\
\text { the province of their department }\end{array}$ \\
\hline Geographical region & $\begin{array}{l}\text { The geographical area of the department where } \\
\text { the patient lived }\end{array}$ \\
\hline Level of education & $\begin{array}{l}\text { The highest level of education achieved by the } \\
\text { patient's parents }\end{array}$ \\
\hline Nutritional condition & $\begin{array}{l}\text { The z-score for the BMI according to age. } \\
\text { The categories were: severely emaciated, } \\
\text { emaciated, normal, at risk of being overweight, } \\
\text { overweight, and obesity }\end{array}$ \\
\hline Etiology & $\begin{array}{l}\text { The pathology identified as being the cause of } \\
\text { the end-stage chronic kidney disease }\end{array}$ \\
\hline Dialysis mode & Either manual or cycler \\
\hline Type of catheter & $\begin{array}{l}\text { A Tenckhoff silicone catheter was used, which } \\
\text { can be either straight or a spiral, as well as } \\
\text { double- or single-cuffed }\end{array}$ \\
\hline Extension change & $\begin{array}{l}\text { The number of times the patient's extension } \\
\text { was changed }\end{array}$ \\
\hline Orifice infection & $\begin{array}{l}\text { The purulent drainage of the exit orifice with } \\
\text { or without skin erythema at the epidermal } \\
\text { interface of the catheter }\end{array}$ \\
\hline Peritonitis & $\begin{array}{l}\text { The cloudy peritoneal fluid with more than } \\
100 \text { leukocytes } / \mathrm{mm}^{3} \text { or the result of a positive } \\
\text { culture }\end{array}$ \\
\hline Number of peritonitis & $\begin{array}{l}\text { The number of episodes of peritonitis that the } \\
\text { patient had experienced }\end{array}$ \\
\hline $\begin{array}{l}\text { Peritoneal dialysis } \\
\text { time }\end{array}$ & $\begin{array}{l}\text { The difference in years between the end date of } \\
\text { the peritoneal dialysis at the Cayetano Heredia } \\
\text { Hospital and the start date of peritoneal dialysis }\end{array}$ \\
\hline \multirow{3}{*}{$\begin{array}{l}\text { Type of peritoneal } \\
\text { membrane }\end{array}$} & The first type of membrane recorded \\
\hline & The last type of membrane recorded \\
\hline & $\begin{array}{l}\text { Mixed: patients with different types of } \\
\text { membrane recorded at the beginning and end }\end{array}$ \\
\hline Final condition & $\begin{array}{l}\text { The patient's condition in June } 2015 \text {, taking into } \\
\text { account whether they were alive or deceased }\end{array}$ \\
\hline Hospitalizations & $\begin{array}{l}\text { The number of times the patient had been } \\
\text { hospitalized for any reason }\end{array}$ \\
\hline $\begin{array}{l}\text { Cause of } \\
\text { Hospitalization }\end{array}$ & The reason why the patient was hospitalized \\
\hline Dialysis operator & $\begin{array}{l}\text { The person who performed the peritoneal } \\
\text { dialysis procedure }\end{array}$ \\
\hline Adequacy of dialysis & $\begin{array}{l}\text { A weekly Kt/V greater than } 2.2 \text { is defined as } \\
\text { normal. It is considered to be normal or below } \\
\text { the normal range }\end{array}$ \\
\hline
\end{tabular}




\section{Conclusion}

Our conclusion after analyzing 15 years of data is that the rate of peritonitis in children was similar to what has previously been described in the literature, and that the factors associated with peritonitis were: being male, orifice infection, extension change, and, as a protective factor, coming from a province rather than the Capital.

\section{Acknowledgment}

Cayetano Heredia University Support Medical Service.

Integral health insurance of the government of Peru for the coverage of care for children with chronic kidney disease in peritoneal.

\section{References}

1. Kidney Disease: Improving Global Outcomes (2013) KDIGO 2012 Clinical Practice Guideline for the Evaluation and Management of Chronic Kidney Disease. Kidney Int Suppl 3: 1.

2. National Kidney Foundation (2002) K/DOQI Clinical Practice Guidelines for Chronic Kidney Disease: Evaluation, Classification, and Stratification. Am J Kidney Dis 39: S1-S266.

3. Harambat J, van Stralen KJ, Jin Kim J, Tizard EJ (2012) Epidemiology of Chronic Kidney Disease in Children. Pediatr Nephrol 27: 363-373.

4. Lagomarsimo E, Valenzuela A, Cavagnaro F, Solar E (1999) Chronic Renal Failure in Pediatrics 1996. Chilean Survey. Pediatr Nephrol 13: 288-291.

5. Loza Munarriz C, Ramos Muñoz W (2016) Análisis de la situación de la enfermedad renal crónica en el Perú, 2015. Ministerio de Salud del Perú, Dirección General de Epidemiología.

6. National Kidney Foundation (2009) KDOQI Clinical Practice Guideline for Nutrition in Children with CKD: 2008 Update. Am J Kidney Dis 53: S1-S124.

7. Sánchez Moreno A, Muley Alonso R (2014) Dialysis peritoneal crónica. Protoc diagn ter pediatr 1: 421-434.

8. Fraser N, K Hussain F, Connell R, U Shenoy M (2015) Chronic peritoneal dialysis in children. Int J Nephrol Renovasc Dis 8: 125-137.

9. Durán Casal D, Florín Yrabién J, Adam Carrillo B, Hernández Alfonso H (2013) Complicaciones infecciosas de la diálisis peritoneal ambulatoria en niños. Revista Cubana de Pediatría 85: 448-454.

10. Sanchez R, Loza R, Loza C, Zegarra L (2013) Surgical Complications and Evolution of Grafts in Children with Renal Transplantation at Cayetano Heredia National Hospital. Open J Nephrol 3: 124-127.

11. Watson AR, Hayes WN, Vondrak K, Ariceta G, Schmitt CP, et al. (2013) Factors Influencing Choice of Renal Replacement Therapy in European Paediatric Nephrology Units. Pediatr Nephrol 28: 2361-2368.

12. Verrina E, Cappelli V, Perfumo F (2009) Selection of Modalities, Prescription, and Technical Issues in Children on Peritoneal Dialysis. Pediatr Nephrol 24: 1453-1464.

13. Loza R, Gutarra E (2014) Noninfectious Complications in Children Undergoing Chronic Peritoneal Dialysis. J Nephrol Ther 4: 3.

14. Barrera P, Zambrano P, Contreras A, Dreves P, Salgado I, et al. (2008) Complicaciones infecciosas en diálisis peritoneal crónica. Rev Chil Pediatr 79: 522-536.

15. Robles-Vázquez N, Aguilar-Kitsu M, Mendoza-Guevara L, MirandaNovales M (2015) Complicaciones infecciosas en niños con enfermedad renal terminal en terapia sustitutiva. Rev Med Inst Mex Seguro Soc 53 3: S246-S252.
16. Areses Trapote R, Sanahuja Ibáñez MJ, Navarro N (2010) Epidemiología de la enfermedad renal crónica no terminal en la población pediátrica española. Proyecto REPIR II. Nefrologia 30: 508-517.

17. Cavagnaro F, Lagomarsino E (1997) Diálisis peritoneal crónica infantil: Estado actual en Chile. Rev Chil Pediatr 68: 78-82.

18. Delucchi A, Contreras A, Bidegain A, Quiero X, Barrera P, et al. (2002) Diálisis peritoneal crónica pediátrica en Chile. Estudio multicéntrico. Rev Chil Pediatr 73: 116-126.

19. Raaijmakers R, Gajjar P, Schröder C, Nourse P (2010) Peritonitis in Children on Peritoneal Dialysis in Cape Town, South Africa: Epidemiology and Risks. Pediatr Nephrol 25: 2149-2157.

20. Durán Casal D, Florín Yrabién J, Adam Carrillo B (2015) Diálisis peritoneal domiciliaria en niños, experiencia en el Hospital Pediátrico Centro Habana. Revista Cubana de Pediatría 87: 205-215.

21. Munshi R, Sethna CB, Richardson T, Rodean J, Al-Akash S, et al. (2018) Fungal Peritonitis in the Standardizing Care to Improve Outcomes in Pediatric End Stage Renal Disease (SCOPE) Collaborative. Pediatr Nephrol 33: 873-880.

22. Sethna CB, Bryant K, Munshi R, Warady BA, Richardson T, et al. (2016) Risk Factors for and Outcomes of Catheter-Associated Peritonitis in Children: The SCOPE Collaborative. Clin J Am Soc Nephrol 11: 15901596.

23. Bordador EB, Johnson DW, Henning P, Kennedy SE, Mc Donald SR, et al. (2010) Epidemiology and Outcomes of Peritonitis in Children on Peritoneal Dialysis in Australasia. Pediatr Nephrol 25: 1739-1745.

24. Jellouli M, Ferjani M, Abidi K, Hammi Y, Boutiba I, et al. (2015) Peritonitis in Pediatric Patients Receiving Peritoneal Dialysis. Nephrol Ther 11: 558-563.

25. Chadha V, Schaefer FS, Warady BA (2010) Dialysis-associated Peritonitis in Children. Pediatr Nephrol 25: 425-440.

26. Feneberg R, Warady BA, Alexander SR, Schaefer F, International Pediatric Peritonitis Registry (2004) The International Pediatric Peritonitis Registry: A Global Internet-Based Initiative in Pediatric Dialysis. Perit Dial Int 24: S130-S134.

27. NAPRCTCS (2003) North American Pediatric Renal Transplant Cooperative Study. Annual Report.

28. NAPRTCS (2011) North American Pediatric Renal Trials and Collaborative Studies. Annual Dialysis Report.

29. de Bustillo EM, Borrás F, Gómez-Roldán C, Pérez-Contreras FJ, Olivares J, et al. (2011) Impacto de las peritonitis en la supervivencia a largo plazo de los pacientes en diálisis peritoneal. Nefrologia 31: 723-732.

30. Chesnaye NC, Schaefer F, Groothoff JW, Bonthuis M, Reusz G, et al. (2016) Mortality Risk in European Children With End-Stage Renal Disease on Dialysis. Kidney Int 89: 1355-1362.

31. Chesnaye NC, van Stralen KJ, Bonthuis M, Harambat J, Groothoff JW, et al. (2018) Survival in Children Requiring Chronic Renal Replacement Therapy. Pediatr Nephrol 33: 585-594. 